\title{
RELATOS DE EXPERIENCIA

\section{Duas décadas da Política Nacional de Educação Ambiental: percepções de professores no contexto de uma escola pública de Pernambuco}

Everaldo Nunes de Farias Filho, II

Carmen Roselaine de Oliveira Farias ${ }^{\mathrm{III}, \text { IV }}$

http://dx.doi.org/10.24109/2176-6681.rbep.101i258.4325

Universidade Federal Rural de Pernambuco (UFRPE). Recife,

Pernambuco, Brasil. E-mail: <everaldo_nff@hotmail. com>; <https://orcid. org/0000-0003-1414-3291>.

II Doutor em Ensino das Ciências e Matemática pela Universidade Federal Rural de Pernambuco (UFRPE). Recife, Pernambuco, Brasil.

III Universidade Federal Rural de Pernambuco (UFRPE) Recife, Pernambuco, Brasil. E-mail:<crofarias@gmail. com>; <https://orcid. org/0000-0001-8823-7771>.

Iv Doutora em Educação pela Universidade Federal de São Carlos (UFSCar). São Carlos, São Paulo, Brasil.

\section{Resumo}

O artigo é um relato de experiência e tem como objetivo compreender as percepções que um grupo de professores da educação básica possui acerca do texto da Política Nacional de Educação Ambiental (Pnea) e apresentar uma metodologia aplicada à análise e discussão coletiva do texto da lei em um contexto de formação continuada de professores. O estudo fez parte de uma pesquisa de mestrado que investigou processos de construção de significados referentes à Pnea durante a elaboração de um projeto curricular de educação ambiental (EA) no contexto da escola. A metodologia empregada incluiu a leitura coletiva e reflexiva do texto da política, usando situações fictícias para suscitar o debate. A análise dos dados dialoga com referenciais teóricos da vertente crítica da EA. Como principais resultados, notamos que os participantes tendem a considerar a lei um documento acabado a ser implementado de modo direto na prática. Poucos professores emitiram posicionamentos críticos a respeito da Pnea. A forma de inserção da EA em contextos escolares, a formação 
de professores em EA, a fiscalização do cumprimento das orientações da Pnea e a participação ativa da sociedade nos problemas ambientais foram os temas que emergiram com maior intensidade nas discussões entre os professores.

Palavras-chave: estudo de caso; política ambiental; prática de educação ambiental.

\section{Abstract \\ Two decades since the National Environmental Education Policy: views of teachers in the context of a public school in Pernambuco}

This is an experience report that aims to comprehend the perceptions of a group of basic education teachers over the National Environmental Education Policy (PNEA). It also presents the methodology used to analyze and collectively discuss the text of the law in the context of teacher's continuing education. This study was part of a master's research on the processes of meaning construction related to PNEA that took place during the development of a curriculum project for environmental education (EE) in the school context. The methodology included the collective and reflective reading of the policy text, using fiction to arouse debate. Data analysis dialogues with theoretical references of EE's critical aspect. As main results, it was observed that participants tend to see the law as a finished document to be directly implemented. Few teachers issued critical opinions on the PNEA. Themes such as EE's insertion in school, teacher education in EE, enforcement of PNEA guidelines, and the active participation of society in environmental issues emerged most intensely in discussions among teachers.

Keywords: case study; environmental education practice; environmental policy.

\section{Resumen \\ Dos décadas de la Política Nacional de Educación Ambiental: percepciones de profesores en el contexto de una escuela pública de Pernambuco}

El presente artículo es un relato de experiencia y tiene como objetivo comprender las percepciones que un grupo de profesores de la educación básica, de diferentes áreas del conocimiento, posee del texto de la Política Nacional de Educación Ambiental (PNEA) y presentar una metodología aplicada para análisis y discusión colectiva del texto de la ley. El estudio formó parte de una investigación de maestría en el contexto de un curso de 
formación en educación ambiental (EA) para profesores, visando conocer las percepciones de los docentes sobre la PNEA. En este estudio, utilizamos como metodología la lectura reflexiva y colectiva del texto de la política, usando textos ficticios conteniendo temas controvertidos en el sentido de estimular y promover una discusión del texto de la ley por los participantes. El análisis de los datos se hizo a partir de un referencial teórico de la vertiente crítica de la educación ambiental. Como principales resultados de la investigación, percibimos que la mayoría de los docentes participantes ve la ley como un documento acabado e inalterable que debe ser cumplido. En esta investigación, pocos profesores emitieron posicionamientos críticos sobre la PNEA. La forma de inserción de la EA en contextos escolares, la promoción de la EA, la formación de profesores en EA, fiscalización del cumplimiento de las orientaciones de la PNEA y la participación activa de la sociedad ante los problemas ambientales fueron los temas que emergieron con mayor intensidad en las discusiones promovidas por los profesores de la escuela estudiada.

Palabras clave: educación ambiental; formación de profesores, Política Nacional de Educación Ambiental.

\section{Introdução}

A Lei Federal no 9.795, de 27 de abril de 1999, que instituiu a Política Nacional de Educação Ambiental (Pnea) completou duas décadas de existência. A despeito de existirem documentos nacionais anteriores de grande relevância para as questões ambientais ${ }^{1}$, a Pnea é considerada um marco na educação ambiental (EA) brasileira, por ser o primeiro texto legal a tratar exclusivamente da EA como direito educacional (Maia et al., 2013). De acordo com Viezzer (2008), a Pnea surgiu em um contexto histórico-político-social influenciado pelos debates ambientais difundidos em níveis nacional e internacional, cujos expoentes foram a Conferência das Nações Unidas sobre Meio Ambiente e Desenvolvimento (Rio 92) e o Fórum Brasileiro das Organizações Não Governamentais e Movimentos Sociais, ambos ocorridos no Rio de Janeiro em 1992.

O Projeto de Lei $\mathrm{n}^{\circ} 3.792$ que precedeu à Pnea tramitou na Câmara dos Deputados no período de 1993 a 1999, ano da sua promulgação, e contava com 22 artigos originais. O período em que prosseguiu na forma de projeto de lei até sua instituição foi permeado de disputas de poder e jogos de interesse e teve como um dos resultados finais o veto do artigo 18, que destinava $20 \%$ dos recursos arrecadados da aplicação de multas decorrentes do descumprimento da legislação ambiental para o custeio de ações de educação ambiental, reduzindo a quantidade de artigos para 21.

Desde o ano de sua promulgação, diversos autores têm realizado estudos com o objetivo de analisar o texto da Pnea, apontando o que consideram ser os acertos e as incoerências da trajetória da EA no Brasil (Layrargues, 
2002; Lopez Velasco, 2002; Pedrini, 2002; Rodrigues; Guimarães, 2010; Janke, 2012; Maia et al., 2013). Nota-se que, mesmo contando com vinte anos, ainda se encontram na literatura recente pesquisas discutindo práticas pedagógicas em face da Pnea. Dias e Oliveira (2014) trazem em seu estudo uma reflexão sobre a Pnea e a influência que exerce numa escola pública municipal no estado da Bahia. Em uma investigação mais hodierna, Azevedo, Costa e Santos (2017) analisam os projetos de extensão e pesquisa realizados por instituições de ensino públicas federais em duas cidades mineiras, com foco na aplicação da Pnea.

A despeito de ser uma lei federal que traz orientações gerais sobre a inserção da educação ambiental na escola, em uma pesquisa anterior, constituímos evidências do desconhecimento do texto da Pnea - e de outros documentos igualmente importantes ${ }^{2}$ - pela maioria dos professores de uma escola da educação básica do interior de Pernambuco (Farias Filho, 2014).

Vale salientar que não corroboramos o pensamento de que uma política educacional tenha de ser implementada na escola pelos seus atores de forma acrítica e ingênua. Ao contrário, concordamos com a ideia defendida por Ball, Maguire e Braun (2016) de que a escola também é um espaço de criação de políticas e que, quando essas chegam ao contexto escolar, são reinterpretadas e recriadas por meio de ajustes e adaptações dos professores e demais atores educativos (Mainardes; Gandin, 2013). Seguindo esse raciocínio, Marcondes, Freund e Leite (2017, p. 1032) dizem que "professores e gestores são protagonistas da política, mas a sua atuação nem sempre é coerente. Eles realizam o que podem dentro dos limites que lhes são impostos".

A Pnea traz orientações para inserir a EA em vários contextos, entre eles o da escola. Entretanto, essa e outras políticas referentes à EA precisam ser lidas e interpretadas por professores e demais atores da escola básica a fim de discutirem as contribuições e limitações delas para construção do currículo e execução das práticas pedagógicas. Nesse sentido, os professores precisam conhecer a natureza epistemológica dos discursos de EA presentes na Pnea e assumir posições críticas em relação às suas orientações em um contexto de discussão coletiva com seus pares. A ação de estudar políticas educacionais de EA no chão da escola pelos docentes, de forma conjunta, estimula o debate entre diferentes concepções de ambiente e de educação ambiental, o aprendizado coletivo e a construção de novos saberes no campo socioambiental. Esse contexto (escola) se configura, dessa maneira, como espaço de formação continuada em EA para docentes em exercício, minimizando algumas lacunas na sua formação inicial.

Vinte anos passados desde a promulgação da Pnea, vemos que continuam sendo pertinentes pesquisas sobre a EA nas escolas, não somente pelo fato de essa lei permanecer vigente, mas por continuar sendo uma importante base normativa para a EA em espaços educativos escolares e não escolares. Acreditamos que a leitura crítica do texto da Pnea e de outras políticas referentes ao tema torna-se imprescindível a todos os professores e lideranças na escola, para que se avance no processo de mudanças nos currículos e nas práticas pedagógicas em direção à educação ambiental.
2 Referimo-nos aqui, em particular, às Diretrizes Curriculares Nacionais para a Educação Ambiental (Resolução CNE n 2, de 15 de junho de 2012. Parecer CNE $n^{\circ} 14$, de 6 de junho de 2012). 
Nesse sentido, este trabalho tem por objetivo compreender as percepções que um grupo de professores da educação básica possui acerca do texto da Política Nacional de Educação Ambiental e apresentar uma metodologia aplicada à análise e discussão coletiva do texto da lei em um contexto de formação continuada de docentes.

\section{O caminho percorrido}

Este estudo fez parte da pesquisa de mestrado do primeiro autor que foi desenvolvida em uma escola pública municipal do interior de Pernambuco com um grupo de nove professores de diferentes áreas do conhecimento, os quais lecionam para alunos do $6^{\circ}$ ao $9^{\circ}$ ano do ensino fundamental. $\mathrm{Na}$ pesquisa, tomamos algumas precauções éticas, como obter a anuência dos sujeitos para participarem dela, e mantivemos o anonimato total da escola e dos participantes, que receberam nomes fictícios de letras do alfabeto grego a fim de se preservar sua identidade. ${ }^{3}$

Os dados usados nas análises foram constituídos em um dos seis encontros de um minicurso de educação ambiental oferecido aos docentes, que teve como tema central a leitura e discussão do texto da Pnea. Assim, realizamos nesse encontro uma oficina para análise e discussão dessa política visando fazer com que os professores lessem o documento, debatessem seu conteúdo e emitissem suas considerações sobre ele.

Apesar de algumas ideias presentes no texto da Pnea permearem as discussões dos professores sobre EA, constatamos que a maioria deles não conhecia o documento. Nesse sentido, a leitura do texto da Pnea pelos

Para a coleta de dados, tomamos por base o inciso VII do art. $1^{\circ}$ da Resolução CNS n 510/2016, que informa sobre a desnecessidade de registro deste estudo no Comitê de Etica em Pesquisa e na Comissão Nacional de Etica em Pesquisa (CEPConep), por se tratar de uma investigação que objetiva o aprofundamento teórico de situações que emergiram espontânea e contingencialmente na prática profissional nas escolas analisadas e que não revela dados que possam identificar os sujeitos da pesquisa. O consentimento livre e esclarecido foi dado pelos professores que aceitaram participar do estudo e foi obtido oralmente, antes do começo do trabalho de campo, de forma explícita. Vale salientar que não houve participação de crianças, adolescentes e de pessoas em situação de diminuição de sua capacidade de decisão. docentes era extremamente necessária para entendermos como eles a recontextualizavam na produção do currículo em EA na escola.

Para estimular a leitura crítica desse documento, utilizamos como recurso metodológico textos escritos de três casos fictícios. Cada caso apresentava uma escola hipotética como cenário e narrava reuniões entre atores educacionais (personagens) que debatiam sobre a inserção da EA em contextos escolares. As discussões narradas nesses casos referiam-se a trechos do texto da Pnea. Dessa forma, pedimos aos professores que se dividissem em três equipes compostas de três participantes. Cada equipe recebeu um caso que se referia a uma escola diferente.

As três escolas fictícias foram denominadas de Escola João Correia, Escola Novo Horizonte e Escola Jurema Pessoa, situadas no município fictício de Floresta dos Leões. As personagens eram diretores, coordenadores, merendeiros e, na maior parte, professores. Todos os casos iniciam as histórias narrando que os professores das três escolas participaram de uma palestra intitulada $A$ degradação do meio ambiente pela ação humana, promovida pela secretaria municipal de educação. Após as discussões realizadas na palestra, as escolas teriam sido estimuladas a inserir a EA em suas atividades. É justamente essa inserção que as personagens discutem em cada caso, emitindo e justificando suas opiniões. 
A atividade foi realizada em duas etapas. Na primeira, os professores foram organizados em três grupos e cada grupo recebeu um caso para ler e discutir antes da leitura do texto da Pnea. Como cada caso abordava partes diferentes da lei que tratam de temas passíveis de debates, provocamos os docentes a emitirem suas considerações sobre as falas das personagens e a revelarem suas concepções sobre os temas tratados. A síntese dessa discussão é descrita no Quadro 1.

\section{Quadro 1 - Principais temas discutidos pelos professores a partir da leitura dos casos}

\begin{tabular}{|l|l|}
\hline \multicolumn{1}{|c|}{ Tema discutido } & \multicolumn{1}{c|}{ Concepção dos professores } \\
\hline $\begin{array}{l}\text { Responsabilidade de } \\
\text { promoção da EA }\end{array}$ & Governo, indústrias, escola e indivíduos. \\
\hline Concepção de EA & $\begin{array}{l}\text { Forma de conscientizar e transformar os } \\
\text { indivíduos em cidadãos críticos em relação às } \\
\text { questões ambientais. }\end{array}$ \\
\hline Inserção da EA na escola & $\begin{array}{l}\text { Não deve ser trabalhada como disciplina } \\
\text { específica do currículo. }\end{array}$ \\
\hline $\begin{array}{l}\text { Fiscalização do } \\
\text { cumprimento da Pnea }\end{array}$ & $\begin{array}{l}\text { Dever do poder público e de cada indivíduo da } \\
\text { sociedade. }\end{array}$ \\
\hline
\end{tabular}

Fonte: Elaboração própria.

A segunda etapa implicou a reavaliação dos casos pelos professores, mas, desta vez, utilizando o texto da Pnea para interpretar o caso e as posições das personagens. O objetivo era que os professores avaliassem a situação descrita à luz do texto da Pnea. Da discussão, resultou o Quadro 2.

\section{Quadro 2 - Análise dos casos a partir da leitura da Pnea}

\begin{tabular}{|l|l|l|}
\hline \multicolumn{1}{|c|}{ Tema discutido } & \multicolumn{1}{|c|}{ Concepção dos professores } & Relação com o texto da Pnea \\
\hline $\begin{array}{l}\text { Promoção da EA } \\
\text { Inserção da EA na } \\
\text { escola }\end{array}$ & $\begin{array}{l}\text { Dever do governo e do cidadão. } \\
\text { disciplina específica do currículo. }\end{array}$ & $\begin{array}{l}\text { Concordam com o art. } 3^{\circ} . \\
\text { Concordam com o § } 1^{\circ} \text { do art. }\end{array}$ \\
\hline $\begin{array}{l}\text { Formação inicial e } \\
\text { continuada em EA }\end{array}$ & $\begin{array}{l}\text { Não é cumprida e fiscalizada pela } \\
\text { lei. }\end{array}$ & $\begin{array}{l}\text { Criticam a falta de fiscalização } \\
\text { da orientação do art. 9 } 9^{\circ} \text { e do } \\
\text { parágrafo único do art. } 11 .\end{array}$ \\
\hline $\begin{array}{l}\text { Disseminação da } \\
\text { EA pela mídia }\end{array}$ & $\begin{array}{l}\text { A EA deve ser disseminada pela } \\
\text { mídia em horários apropriados } \\
\text { com bastante audiência. }\end{array}$ & $\begin{array}{l}\text { Concordam com o parágrafo } \\
4^{\circ} \text { do art. } 3^{\circ}, \text { mas questionam } \\
\text { o cumprimento dessa diretriz } \\
\text { pelas emissoras de TV. }\end{array}$ \\
\hline Ecoturismo & $\begin{array}{l}\text { Atividades de ecoturismo } \\
\text { correspondem a ações de } \\
\text { promoção da EA. }\end{array}$ & $\begin{array}{l}\text { Concordam com o parágrafo VII } \\
\text { do art. 13. }\end{array}$ \\
\hline
\end{tabular}

Fonte: Elaboração própria.

Para realizarmos a análise das discussões dos casos nas duas etapas, recorremos à transcrição completa dos diálogos e à interpretação de textos, destacando trechos considerados relevantes nas falas das personagens, 
chamadas de unidades de significados. A constituição dessas unidades levou em conta nossa interpretação do texto e do contexto e seu significado compartilhado.

\section{Análise e discussão dos resultados}

Esta seção está organizada em dois momentos. No primeiro, são apresentados os resultados da análise dos debates dos grupos antes da leitura e a discussão conjunta sobre o texto da Pnea. No segundo, é exibida a reavaliação dos casos, mas, desta vez, levando em consideração as premissas daquela política.

Primeiro momento: uma leitura descompromissada dos casos

O primeiro grupo foi composto pelas professoras Delta, Gama e Ômega e analisou o caso da Escola João Correia. Entre as discussões realizadas na reunião, destacam-se a definição da responsabilidade pela promoção da EA na escola, a forma de inserção da EA no cotidiano escolar e quais docentes devem ter a incumbência de planejar e executar práticas ambientais nesse estabelecimento.

O Quadro 3 apresenta na coluna da esquerda trechos do caso fictício e na coluna da direita as unidades de significados correspondentes, constituídas a partir da análise das discussões dos professores.

\section{Quadro 3 - Análise do diálogo das personagens da Escola João Correia}

Fala das personagens (caso fictício)

Professor Antônio: Essa história de trabalhar EA é para os ecologistas e ambientalistas. O governo é que tem a obrigação de investir nesses profissionais para que eles desenvolvam pesquisas sobre o Meio Ambiente. A escola já tem muitas outras obrigações. Esse negócio de EA não é tarefa da escola.

Professora Regina: Eu concordo com o professor Antonio de que EA não faz parte das atribuições do professor na escola. Mas quem polui o ambiente são as fábricas e as indústrias. Então, é obrigação delas cuidarem do ambiente. O governo tem que fiscalizar isso.
Unidades de significado (falas dos professores)

Professora Ômega: (...) tá empurrando as coisas, a responsabilidade para as fábricas, para o governo. E, no entanto, a gente tava aqui vendo, o único meio que pode levar isso adiante é a escola. A escola é o único meio em que pode haver a conscientização dos nossos alunos, em casa e na escola.

Professora Iota: Não acho que a escola seja o único. Eu acho que a escola é um grande meio, mas ela não seja de espécie nenhuma, de categoria nenhuma, o único meio de se influenciar, de se aplicar a EA.

Professora Gama: A escola é a grande incentivadora dessa questão ambiental. 


\section{Quadro 3 - Análise do diálogo das personagens} da Escola João Correia

Professor Joaquim: Acho que a EA poderia ser trabalhada pela escola por causa da palavra Educação. Mas o que iríamos desenvolver em nossos alunos?

Professor Antônio: Deixa a escola fora disso. Não temos obrigação com EA. O governo que cuide disso. Já tem a imprensa pra ajudar. A televisão já faz um favor ao governo colocando programas ecológicos em sua programação.
Professora Delta: (...) não é só papel dos ecologistas nem dos ambientalistas trabalharem a EA, mas que se comece a ver de forma diferente. Essa conscientização comece do ambiente doméstico, do ambiente escolar, até chegar à comunidade, até pra inserir a comunidade.

Professora Omega: Embora saibam da importância da EA, não existe uma preocupação por parte dessa escola em trabalhar com esses temas, de transformar os estudantes em cidadãos conscientes dos problemas ambientais.

Fonte: Farias Filho (2014, p. 89)

O trecho do caso da Escola João Correia mostra um diálogo entre os professores em que se discute de quem é a incumbência de fomentar a EA. O objetivo da análise foi compreender que visão os professores têm acerca da responsabilidade da escola e dos docentes na promoção da educação ambiental. Ao analisarmos os discursos dos sujeitos, percebemos que emerge a ideia de que a EA no contexto escolar se configura como "meio" para conscientizar os indivíduos sobre a questão ambiental.

Apesar de nesse momento ainda não terem lido o texto da lei, as professoras argumentam que o dever de promover a EA não é só do governo ou de entidades poluidoras. Elas concordam que a escola tem um papel fundamental no desenvolvimento de ações em EA - mesmo não sendo o único caminho, como diz a professora Iota - por meio da conscientização dos indivíduos para, a partir daí, atingir toda a sociedade.

Podemos perceber que tanto a professora Ômega quanto a professora Delta concebem a EA como ato de conscientizar os alunos. Nesse sentido, a visão das docentes coincide com um dos objetivos da educação ambiental elencados na Pnea, situado no artigo 5, inciso III. Contudo, verifica-se que a professora Ômega, no último trecho, aponta a EA como forma de "transformar os estudantes em cidadãos conscientes dos problemas ambientais". Observamos, portanto, que a concepção de EA dessa professora vai além do objetivo citado na Pnea. Ela avança para uma concepção de EA numa perspectiva transformadora. $O$ ato de transformar o indivíduo em um cidadão consciente da problemática ambiental preconizado pelo Tratado de Educação Ambiental para Sociedades Sustentáveis e Responsabilidade Global e pela Resolução n ${ }^{0}$ 2, de 15 de junho de 2012, que apresenta as Diretrizes Curriculares Nacionais de Educação Ambiental (DCNEA), não está previsto na Pnea, o que faz com que seu tex to funcione como um dispositivo de "reprodução social" e não de "transformação social" (Layrargues, 2002; Rodrigues; Guimarães, 2010). 
A segunda equipe, formada pelas professoras Zeta, Teta e Sigma, analisou o caso da Escola Novo Horizonte. A discussão teve como temas centrais a formação inicial e continuada de professores em EA e a forma como esta deve ser inserida na escola, conforme o Quadro 4.

\section{Quadro 4 - Análise das falas das personagens da Escola Novo Horizonte}

Fala das personagens (caso fictício)

Professora Conceição: Minha irmã trabalha como professora na Escola João Correia. Ela me falou que os professores de lá estão divididos. Não decidiram se eles vão trabalhar com EA somente nas datas comemorativas ou com projetos durante todo o ano letivo.

Professor Malaquias: Rapaz! Falar de EA dentro da escola não é tão simples assim. Nós não fomos formados para isso. Não temos como falar de uma coisa que é desconhecida pra nós.

Após essas discussões, os professores dessa escola chegaram a um consenso de que a EA deverá ser inserida na escola como uma disciplina nas turmas do $6^{\circ}$ ao $9^{\circ}$ ano do ensino fundamental e no ensino médio. Nas turmas do $1^{\circ}$ ao $5^{\circ}$ ano do ensino fundamental, a EA será trabalhada com projetos interdisciplinares. Os professores consideraram que as turmas de educação infantil não terão a inserção da EA, pois se tratava de crianças que ainda não tinham maturidade suficiente para entender essa temática. Decidiram ainda que a EA não seja desenvolvida nas turmas de EJA, educação especial e cursos profissionalizantes, pois estes não fazem parte do campo da educação escolar formal.
Unidades de significado (fala dos professores)

Professora Teta: (...) a EA faz parte do nosso cotidiano de um modo geral, então esse tema tem que ser trabalhado durante todo o ano letivo. Isso é o que eu defenderia se eu fosse dessa escola.

Professora Zeta: O que me chamou a atenção foi essa parte. Achei um absurdo isso aí.

Professora Teta: (...) a própria lei vai mostrar pra gente que a EA deve ser inserida em todas as modalidades de forma interdisciplinar. (...) eu não acredito que uma EA deva ser trabalhada como disciplina isolada. Não é de forma isolada que tem que ser trabalhada. (...) se a gente exclui a educação infantil da possibilidade de absorver o conhecimento, da EA, a gente tá matando essa semente antes mesmo de plantá-la.

Fonte: Farias Filho (2014, p. 91)

Ao analisar a discussão apresentada no texto da Escola Novo Horizonte, as professoras dessa equipe discordaram das concepções das personagens. Para a professora Teta, a EA deve estar presente em todas as modalidades de ensino e não deve ser desenvolvida por meio de uma disciplina específica do currículo, visão defendida nos estudos de autores como Pombo, Levy e Guimarães (1994) e González-Gaudiano (2005). Verificamos que essa ideia se assemelha à orientação trazida pela Pnea, ao estabelecer que a EA deva ser inserida em todos os níveis e modalidades de ensino, não devendo ser implantada como uma disciplina específica na educação básica. Dessa forma, compreendemos que a opinião da professora Teta está imbuída das ideias trazidas pela Pnea, visto que a docente já conhecia o texto da lei quando a cita para defender a interdisciplinaridade da EA. 
A última equipe foi constituída pelos professores Pi, Iota e Capa, que analisaram os discursos das personagens da Escola Jurema Pessoa. A discussão envolveu temas como a veiculação da EA pela mídia, as ações de EA desenvolvidas pela iniciativa privada, a utilização de recursos financeiros em ações de EA e a fiscalização do cumprimento das leis de EA no País. Todavia, nessa primeira análise, o que mais chamou a atenção dos professores foi a parte que trata da fiscalização das leis de EA, como está explicitado no Quadro 5.

\section{Quadro 5 - Análise das falas das personagens da Escola Jurema Pessoa}

Fala das personagens (caso fictício)

Unidades de significado (fala dos professores)

Professor Pedro: Na cidade onde meus pais moram tem uma reserva ecológica, mas os moradores da região não estão colaborando. Eles estão jogando lixo nas proximidades da reserva. O governo deveria cuidar disso.

Professora Gilda: Também tudo é o governo! O povo é mal-educado mesmo. O governo não tem nada a ver com isso. Isso acontece porque essas pessoas não têm nenhuma educação doméstica.

Professor Lima: O governo tem participação nisso sim. Vocês sabiam que já existem leis que tratam sobre a EA? Mas para essas leis serem cumpridas é necessário que elas saiam do papel e comecem a ser executadas. Tem que haver um órgão que seja responsável pelo cumprimento dessas leis.

Professor Pedro: Mas não tem como essas leis nacionais serem cumpridas num país tão grande como o Brasil. Elas são criadas lá em Brasília. Quem vai fiscalizar? Não há como.

Professor Lima: Pois é. Acho que deveriam ser criadas comissões locais para fiscalização.
Professora Capa: Quando fala aqui [no texto] esse país é muito grande. Não tem como o governo fiscalizar tudo isso, mas entra a conscientização de cada um.

Professor Pi: (...) são os municípios e os estados que fazem o governo ver no todo, no geral. (...) existe o presidente (da República), mas o presidente não vai poder conhecer toda a realidade de um país. Ele não vai estar lá em todos os momentos. Então tem que ter alguém de perto, alguém daquela realidade, daquele meio, que possa conhecer o que é que a região, a cidade precisa para estar acompanhando durante um tempo maior. (...) Quando você pensa de baixo pra cima, começa a surtir efeito. Tipo um pequeno município toma iniciativa e faz um projeto que vai começar a ser copiado, e isso tá propagando.

(...)

Eu acho que em muitas cidades daqui dessa região daria muito bem pra ter um aterro sanitário, porque um aterro sanitário você precisa de uma área para que se façam aterros gradativos e que você passa algumas tubulações para aproveitar esses gases que podem ser aproveitados, colocar algumas indústrias de pequeno porte pra funcionar e também para produzir energia elétrica. Se você passar em cada cidade, dá pra se ver cada lixão!

Fonte: Farias Filho (2014, p. 92)

Diante desses discursos, fica claro que os professores concordam que o governo deve fiscalizar o cumprimento das leis ambientais no País. Todavia, essa fiscalização não deve ser incumbência somente do poder público, mas 
também de toda a sociedade. Percebemos que a visão da professora Capa se equipara com a orientação trazida pelo inciso VI do artigo $3^{\circ}$ da Pnea, que diz que é incumbência da "sociedade como um todo manter atenção permanente à formação de valores, atitudes e habilidades que propiciem a atuação individual e coletiva voltada para a prevenção, a identificação e a solução de problemas ambientais" (Brasil, 1999).

Nesse sentido, o professor Pi afirma que a fiscalização do cumprimento das leis se tornaria mais efetiva se existissem, em nível municipal e estadual, acompanhamento de perto das necessidades da população e execução de ações locais em prol do meio ambiente. De acordo com o professor Pi, essas ações - como a construção de aterros sanitários pelos municípios - ajudam a conservar o meio ambiente, eliminando os lixões, e atuam na geração de emprego e renda para a população da região por meio da instalação de indústrias e produção de energia a partir da captação dos gases.

\section{Segundo momento: os casos discutidos à luz da Pnea}

Depois dos debates, iniciamos a segunda etapa da atividade, sugerindo que os professores reavaliassem os casos, mas, desta vez, utilizando o texto da Pnea para deliberar sobre as falas das personagens. O objetivo era que os docentes julgassem se as falas das personagens estavam de acordo com as orientações da Pnea. A realização dessa etapa permitiu que alcançássemos duas metas: a primeira foi fazer com que os participantes realizassem uma leitura mais atenta do texto da lei e a segunda foi coletar dados, a partir de suas falas, que nos permitissem compreender um pouco sobre o que os professores concordavam ou discordavam acerca das orientações trazidas pela Pnea. Quanto ao caso da Escola João Correia, a primeira equipe a apresentar suas percepções foi o grupo formado pelas professoras Delta, Gama e Ômega. Analisemos o diálogo abaixo:

Professora Delta - [...] A nossa equipe não concordou com o professor Antonio, porque nós achamos que não é só dever dos ecologistas e ambientalistas trabalhar a EA, mas sim de todos, e que devem ser trabalhados desde casa até na escola, pra que eles possam colocar em prática de uma forma geral, na convivência uns com os outros, com a comunidade.

Professora Gama - (..) a gente se baseou no artigo $3^{\circ}(\ldots)$ envolve o poder público, as instituições educativas, órgãos integrantes do Sistema Nacional de Meio Ambiente, os meios de comunicação, as empresas e a sociedade.

Professora Delta - A EA é um compromisso de todos: família, escola e comunidade, conforme o artigo $2^{\circ}$ da lei que estamos em discussão, não é só compromisso da escola ou de uma determinada área ou disciplina, mas que ela deve ser trabalhada por todos, em todas as áreas do conhecimento e para a comunidade de uma forma geral, para que a questão da EA não seja só restrita a leis, mas que seja vivenciada realmente na prática, na educação mesmo, até de um simples papel a ser colocado no lixo até a questão da conscientização, das grandes fábricas, da poluição de uma forma geral. 
Professora Ômega - Outros professores querem que seja somente na matéria de Biologia. A gente chegou a um consenso que isso [EA] deve ser trabalhado em todas as matérias e no dia a dia. Isso aí deve ser um assunto que deve ser conversado principalmente em casa, na família e na escola, ou seja, no todo, na comunidade. (Farias Filho, 2014, p. 95)

Percebemos nesse diálogo que as professoras abordam três pontos em suas considerações: a responsabilidade de promoção da EA, a vivência da EA na prática e a inserção da EA na escola de forma não disciplinar. No debate, as professoras Delta e Ômega afirmam que a responsabilidade de inserir a EA é de todos, devendo começar em casa e na escola com o objetivo de mudar as relações ("convivência") dentro da sociedade ("comunidade"). Quando diz "mas que seja vivenciada realmente na prática, na educação mesmo", a professora Delta destaca a importância da associação entre a teoria e a prática no processo de construção do conhecimento do indivíduo. No que se refere à inserção da EA em contextos escolares, as professoras Delta e Omega concordam com a orientação da Pnea, ao defender sua implantação na escola de forma não disciplinar e contínua. Nessa concepção, as professoras não definem se a EA deve ser implantada na escola numa perspectiva interdisciplinar, multidisciplinar ou transdisciplinar, remetendonos às pesquisas de Lopez Velasco (2002), quando diz que a Pnea orienta para um trabalho "mais que disciplinar" da EA.

A partir da observação desse diálogo, verificamos que, mesmo utilizando o texto da lei para examinar o caso, os posicionamentos dos professores não apresentam alterações expressivas em relação à primeira análise. Consideramos, portanto, que os docentes dessa equipe não se posicionaram contra as orientações trazidas pela Pnea. Diante disso, constatamos que estas emergiram nos discursos dos professores, mesmo desconhecendo o texto da Lei $n^{\circ}$ 9.795/99.

Continuando a discussão da primeira equipe, a professora Gama leu outro trecho do caso, que falava sobre formação em EA. Na sequência, Gama fez a leitura do artigo 11 da Pnea, que trata do processo de formação inicial e complementar em EA para professores. Após essa leitura, surgiu um grande debate sobre o tema formação de professores em EA e a interdisciplinaridade, iniciado pela professora Iota:

\footnotetext{
Professora Iota - Isso de fato não acontece. Eu estou colocando currículo enquanto universidade. Eu fiz Letras. O que foi que a gente viu de interdisciplinaridade dentro do curso de Letras? Então, já começa a partir da formação. Algo que me vai ser exigido, mas em contrapartida não me foi dado. Aí já começa a grande dicotomia da Educação, é assim: exige uma coisa que eu não recebi. (Farias Filho, 2014, p. 96)
}

Em sua fala, a professora Iota faz uma crítica à Pnea, afirmando que as orientações para capacitação dos docentes não são cumpridas pelas universidades no processo de formação inicial do professor. Todavia, quando este ingressa na profissão, vai sofrer cobranças sobre temas que não foram abordados na sua graduação. Essa discussão sobre formação de professores em EA aparece como crítica ao descumprimento da lei pelos sistemas de ensino. 
Dando continuidade, a professora Gama prossegue a leitura do caso, referindo-se a uma personagem do texto que afirma não ser possível trabalhar EA em suas aulas pelo fato de ser professora de Matemática. Analisemos o diálogo que dá continuidade ao debate sobre o tema formação de professores em EA:

Professora Ômega - Não tem nada a ver porque é professor de matemática não sabe trabalhar EA? Por que não? (...) se o professor de Matemática na sala de aula, se o aluno jogou o papel ali, vamos conversar, ó minha gente... quer dizer, no dia a dia, ele sabe tudo sobre como defender.

Professora Iota - Eu não concordo não. Exigir do professor uma superficialidade do assunto. Então ensinar só por ensinar eu acho que não. (...) não se pode cobrar do professor aquilo que ele não tem. Então se eu não dou formação, se a secretaria municipal, se a secretaria estadual de educação não dá formação, como é que ela pode exigir do professor? E lei? Que técnica eu vou ensinar pra que o meu aluno possa aprender? A lei é clara, é ótima, é eficiente, entretanto eu tenho que colocar o seguinte: é a questão da formação do professor. Tem que se mudar de cima pra baixo. Eu não posso exigir lá embaixo que o professor dê, não. Que instrumentalização? (...) Eu acho que tem que ter esse respaldo na lei, tem que ter formação para o professor, tem que ter formação continuada para o professor saber instrumentalizar a EA na escola. (Farias Filho, 2014, p. 97)

Pela análise desse diálogo, verificamos que, enquanto a professora Omega afirma que todos os docentes podem desenvolver atividades de EA na escola, a professora Iota declara que, para que isso ocorra, é preciso primeiro que os professores sejam formados. Para Iota, a lei deve ser cumprida tanto no sentido de requerer que os professores insiram a EA em suas práticas educativas quanto na obrigatoriedade de exigir que sejam proporcionadas formações em EA para os docentes.

Esse debate sobre formação de professores em EA serviu como gancho para que os docentes da segunda equipe iniciassem a apresentação de suas considerações.

Composta pelas professoras Teta, Zeta e Sigma, a segunda equipe analisou o caso da Escola Novo Horizonte e deu continuidade ao debate do grupo anterior. Ao ler um trecho do caso, a professora Sigma relata a fala de uma personagem sobre onde os professores deveriam ser capacitados. Vejamos isso no diálogo abaixo:

Professora Sigma - [...] não é preciso a gente voltar pra universidade, mas sim que o governo, os governantes ofertem subsídios para que possamos construir esse conhecimento.

Professora Iota - É isso que eu não posso exigir do professor que ele não teve formação pra dar uma formação adequada. A gente também tem que fazer um olhar crítico daquilo que está escrito na lei e daquilo que não nos respalda.

Professora Gama - A lei existe, mas ela tem que funcionar de cima pra baixo. Os cursos superiores não trabalham essa questão.

Professora Iota - Nem os cursos de especialização, eles debatem essa questão, que seria uma formação, um lugar propício para o professor se reciclar e dizer: olha, você tem que também, professor, trabalhar com EA. (Farias Filho, 2014, p. 98) 
Analisando esses discursos, verificamos que as professoras reconhecem que a lei prevê formação inicial e continuada em EA para os docentes. O que é questionado por elas é o descumprimento dessa norma da Pnea pelo governo. No trecho "que os governantes ofertem subsídios para que possamos construir esse conhecimento", a professora Sigma atribui às lideranças do governo a incumbência de proporcionar formações aos docentes, necessárias para que estes possam planejar e desenvolver ações em EA. Nesse sentido, os professores apoiam a exigência de capacitação em EA trazida no texto da Pnea. No entanto, reforçam o argumento já citado sobre a contradição de se cobrar ações em EA de professores que não receberam formação nessa área.

Outro ponto que merece destaque é a perspicácia da professora Iota quando sugere que todos os docentes devem analisar criticamente o texto da lei. Esse "olhar crítico" sobre a Pnea deve ser no sentido de buscar embasamento para que o professor se ampare de cobranças infundadas acerca de sua desenvoltura como educador. A despeito de o artigo $9^{\circ}$ da Pnea preconizar a EA nos cursos superiores, as licenciaturas e os cursos de especialização são escopos das críticas desses professores por não promoverem a EA em seus currículos.

Além dos cursos de formação inicial, a formação continuada em EA para professores em atividade, prevista pela Pnea no parágrafo único do artigo 11, é extremamente necessária para o planejamento, o desenvolvimento e a avaliação de ações ambientais na escola. Analisemos o diálogo abaixo:

Professora Sigma - [...] você tem alguma ideia do que seja EA. É claro
que nós temos, porque tem internet, tem livros, mas você precisa ser
direcionado, você precisa ser acompanhado, você precisa ser avaliado.
Como é que eu vou trabalhar essa disciplina? Como é que eu vou avaliar
meu aluno? Realmente tem que ter uma capacitação, tem que ter um
direcionamento. Você fica voando. Eu pesquisei na internet, vi o assunto
e aí? Vou trabalhar como? Como vou avaliar? Como vou ser avaliado?
Então precisa dessa capacitação.

Professora Zeta - [...] é necessário direcionamento e orientação para inserir a EA. Não que ele [professor] não vá buscar. Claro que ele tem que buscar, mas ele tem que ter um direcionamento para buscar. Ele não pode pegar qualquer coisa achando que é EA. (Farias Filho, 2014, p. 99)

As professoras Sigma e Zeta alegam que a capacitação dos docentes em EA se torna imprescindível pelo fato de orientá-las nas pesquisas de temas, no planejamento das ações executadas na escola e na avaliação da construção dos saberes em EA - argumento defendido nos estudos de Dias e Oliveira (2014). Em seu raciocínio, a professora Zeta argumenta que as formações norteiam os docentes para selecionar o que deve ser trabalhado em EA na escola. Diante desses pressupostos, constatamos que as professoras alegam não possuir subsídios para desenvolver ações de EA sem que haja um direcionamento, mesmo reconhecendo que todo docente possui algum tipo de visão sobre a EA.

A despeito das críticas realizadas sobre o descumprimento do artigo 11 da Pnea pelos sistemas de ensino, ainda assim as mesmas professoras 
enxergam que a EA não pode deixar de ser promovida na escola. Podemos observar isso nas falas das professoras Iota e Teta:

Professora Iota - Como educadora, a gente tem mais é que promover ações de cidadania seja ela em que área for. Quando eu coloco aí que cabe também a formação do currículo do professor, não me cabe ficar de braços cruzados sem me movimentar e dizer assim: só porque eu não recebi, também não vou dar. Então eu acho que não cabe também ao professor a acomodação.

Professora Teta - Claro que a gente não vai ficar de braços cruzados esperando que o governo, que os governantes tomem um posicionamento. A gente tem meios de ir buscar informações, mas a gente precisa de algo que seja respaldado, cursos que sejam reconhecidos, para que isso venha valorizar ainda mais o profissional que está correndo atrás de se preparar melhor. (Farias Filho, 2014, p. 100)

Ao enfatizar que a promoção de ações de cidadania - entre elas as de EA - faz parte das atribuições do docente dentro do processo educativo, a professora Iota considera que, mesmo sem receber formação, é auspicioso que os professores executem ações de EA na escola, pois, como defendido nos estudos de Azevedo, Costa e Santos (2017), talvez essas formações jamais ocorram. Corroborando essa concepção, a professora Teta assegura que os docentes possuem alternativas para suprir a ausência de formação em EA. Todavia, reafirma o argumento dos outros professores de que essas capacitações são indispensáveis para ampliar o conhecimento do profissional em EA e valorizá-lo em sua atuação enquanto docente.

Após esse debate, a segunda equipe finalizou suas considerações com uma pequena discussão sobre a forma de inserção da EA na escola. Como sinalizado no início, as professoras dessa equipe não aprovam a criação de uma disciplina específica de EA no currículo. Além de concordarem com a orientação trazida pela Pnea no artigo 10, parágrafo $1^{\circ}$, as docentes justificaram sua alegação declarando que a EA é um tema transversal, devendo permear todas as áreas. Macedo (1998) apresenta a ideia de transversalidade como sendo uma estratégia curricular com o propósito de que a realidade social perpasse por todas as disciplinas. Acompanhemos o diálogo a seguir:

Professora Sigma - [...] de acordo com artigo $10^{\circ}$, do inciso I, declara que a EA deve ser trabalhada de forma integrada.

Professora Teta - E não isolada.

Professora Sigma - Deve ser [EA] integrada, contínua.

Professora Teta - Contínua e permanente. É um tema transversal.

Professora Sigma - Deixa bem claro que não pode ser disciplina.

Professora Iota - Eu acho que ele [o texto da lei] está sendo dúbio quando diz que a EA não deve ser implantada como disciplina específica no currículo de ensino. Quando ele falava de ensino, ele estava falando de todas as instâncias. E nesse capítulo que você está lendo aí, se ele diz isso, ele abre um parêntese e contradiz. E específico ou não é. Pra mim ela não deveria ser tratada como nada de específico. Ela deve ser trabalhada de uma forma integrada como...

Professora Teta - Em todos os níveis. 
Professora Iota - Pronto, em todos os níveis. Vocês tão vendo aí que no artigo 10, no parágrafo I: "A educação ambiental não deve ser implantada como disciplina específica no currículo de ensino." Ele não especificou se era fundamental, se era médio ou superior. Eu entendi que eram todos.

Professora Teta - Aí no $2^{\circ}$ [parágrafo] ele abre a brecha. (Farias Filho, 2014, p. 101)

Observamos que, entre os participantes desse encontro, a professora Iota é a que se posiciona de forma mais crítica em relação ao texto da Pnea. No diálogo atrás citado, ela faz uma crítica ao texto da lei, afirmando que os parágrafos do artigo 10 se contradizem, tornando seu texto ambíguo. Na visão da professora Teta, o parágrafo $2^{\circ}$ do mesmo artigo deixa dúvidas ("abre a brecha") sobre a abordagem disciplinar e não disciplinar da EA.

Continuando o debate, a terceira equipe, composta pelos professores Pi, Iota e Capa, apresentou suas colocações sobre o caso da Escola Jurema Pessoa. A professora Iota realizou a leitura da fala de uma personagem do caso. No texto, a personagem era favorável à exibição de programas como o Globo Ecologia, por apresentar temas ambientais e utilizar a televisão como meio de comunicação que atinge várias pessoas a longas distâncias. Analisemos os trechos a seguir:

\begin{abstract}
Professora Iota - A fala referente à participação da mídia em promover a EA tem respaldo na Lei $n^{\circ}$ 9.795/99, no capítulo I, artigo $3^{\circ}$, no parágrafo $4^{\circ}$, no qual responsabiliza os meios de comunicação em colaborar de maneira ativa e permanente na disseminação de informações e prática educativas. E também no artigo 13, no inciso I, que ele diz aí: "a difusão, por intermédio dos meios de comunicação de massa, em espaços nobres", o que não ocorre, "de programas e campanhas educativas, e de informações acerca de temas relacionados ao meio ambiente". Então a gente sabe que no Globo Ecologia e esses programas que envolvem EA só acontecem em horários impróprios, $6 \mathrm{~h}$ da manhã, 5h da manhã, de madrugada, onde a população não tem acesso. Então já tá aí a lei não sendo cumprida.
\end{abstract}

Professora Teta - Por que não coloca no horário nobre? (Farias Filho, 2014, p. 101)

Verificamos que a crítica apresentada pelas professoras não está direcionada à diretriz da Pnea que orienta a disseminação de temas ambientais por meio dos sistemas de comunicação, mas à desobediência das emissoras de televisão à determinação da lei no que se refere aos horários de exibição desses programas. Os professores enfatizam que os programas que tratam de questões ambientais não alcançam a maior parte da população por serem apresentados em horários incoerentes com a rotina dos indivíduos. A não exibição desses programas em horários nobres, como preconiza a lei, denota a depreciação da EA por parte dos meios de comunicação. A desobediência e a falta de fiscalização do cumprimento da lei, temas discutidos pela equipe durante a primeira etapa da atividade do encontro, reaparecem no discurso.

Outra questão polêmica no debate se refere ao ecoturismo e às trilhas realizadas em áreas verdes. Essa questão emergiu quando foi lido 
um trecho do caso em que uma personagem relata a iniciativa de uma fazenda (propriedade privada) de fazer trilhas na mata organizadas pelos próprios funcionários e destinadas a estudantes e turistas. Os professores julgam que a atitude da fazenda está de acordo com os artigos $3^{\circ}$ e 13 da Pnea. Percebemos que os docentes apoiam esse tipo de atividade e citam lugares da região em que estão inseridos para ilustrar suas opiniões, como explicitado no diálogo abaixo:

Professora Iota - [...] a participação da fazenda em patrocinar visitas às áreas verdes existentes estimula a participação da população a fazerem trilhas, está ancorado no artigo $3^{\circ}$, no inciso $\mathrm{V}$.

Professora Teta - [...] se você for pra Seção III, que fala da EA não formal, aí a gente vê que o artigo 13 trata dessa questão, inclusive colocando essa atividade como ecoturismo.

Professor Pi - Tem uma reserva em Goiana.

Professora Teta - A Aparauá.

Professor Pi - A área é muito preservada. Tem área pra banho e você também pode fazer uma trilha de bote. Você vai e volta por dentro da mata, ou então você vai e volta por outro caminho.

Professora Iota - Aqui também tem, minha gente, só não há a mobilização do poder público. A Serrinha é uma trilha maravilhosa que você faz. Aquilo ali era um ponto de turismo para a região. (Farias Filho, 2014, p. 103)

Percebemos que, em suas descrições, os professores enfatizam que esses locais são áreas preservadas e destacam seu uso apenas para o lazer, para o desenvolvimento de trilhas e como pontos turísticos. Nesse sentido, verificamos que os docentes concebem as ações desenvolvidas em tais locais como práticas de EA.

Conforme citado anteriormente, um dos objetivos do encontro foi propor aos professores uma oportunidade de estudar e debater o texto da Pnea. Verificamos que a oficina desenvolvida no encontro proporcionou aos participantes a aquisição de novos conhecimentos, como é relatado pelo professor PI:

Professor Pi - Sisnama. Primeira vez que eu vi esse nome e esse órgão, Sistema Nacional de Meio Ambiente para mim não existia. Se eu não conhecia, outras pessoas pode ser também que não conheçam, porque não tem aquela disseminação para o público. Só quem sabe é quem está realmente estudando na área, que vai pesquisar e tudo mais. Então, como é que a gente vai promover? (Farias Filho, 2014, p. 104)

Segundo a visão do professor Pi, é importante que se conheçam os órgãos que orientam e fiscalizam ações ambientais. Ele associa a promoção da EA pelos professores ao desenvolvimento de pesquisas e estudos nessa área. Essa concepção é corroborada pela professora Iota:

Professora Iota - Eu acho que precisa ser estudada um pouquinho mais a Política Nacional de Educação Ambiental pra que os estados, os municípios e afins possam fazer o cumprimento da lei. Deliberar seus documentos. Se eu não conheço o objetivo específico, como é que eu vou implantar uma política? Se eu não conheço a Lei Nacional, o Sistema 
Nacional de Educação, em EA, como é que eu vou fazer? Implantar, em fazer valer? E aí a gente só fica na perspectiva de cobrança de prefeitura, dos estados e dos municípios. (Farias Filho, 2014, p. 104)

A professora Iota reconhece a necessidade e a importância do estudo da lei no sentido de entender as diretrizes trazidas em seu texto. Para ela, a compreensão crítica da Pnea e de outros documentos educacionais é imprescindível para que se desenvolvam ações de EA. Percebemos nessa fala que a professora Iota enxerga que a compreensão do texto da lei leva os indivíduos a, além de cobrar do governo, materializar a política mediante ações.

O último tópico debatido pela terceira equipe se refere aos recursos financeiros destinados ao financiamento de ações em EA. Esse tópico apareceu após a leitura da fala de uma personagem do caso. Nele, a personagem defendia que os recursos financeiros são obrigação exclusiva do governo federal, deixando estados e municípios isentos dessa responsabilidade. Os professores da equipe discordaram da personagem. Vejamos um trecho da fala da professora Iota:

Professora Iota - Não é aquilo que eu concordo. Se eu ensino na escola que não se deve jogar lixo nas ruas, que vai fechar as galerias, que vai entupir e que vai acontecer alagamento, isso não vai haver respaldo no poder público? Não vai haver ressonância no gasto do governo? Vai refletir. Se eu ensino o aluno a jogar o lixo no chão, ou melhor, jogar o lixo no lugar adequado, eu vou evitar que eu tenha mais empregados pra isso, pra varrer as escolas e não sujar as ruas. Deveria se investir na conscientização da população e não no enfrentamento, porque eu vou contratar pessoas pra pegar o lixo. (Farias Filho, 2014, p. 104)

A professora Iota se posiciona contra a fala da personagem do caso e atribui também aos estados e municípios a responsabilidade de financiar ações de EA. Segundo a professora, seria mais vantajoso para o governo desenvolver e incentivar ações de conscientização da população no sentido de evitar problemas socioambientais ("lixo") em vez de enfrentá-los, o que custaria mais caro para o governo e para a própria população. A discussão finalizou as considerações dos professores da terceira equipe e, dessa forma, concluímos a leitura e os debates sobre a Pnea.

\section{Considerações finais}

Consideramos que a realização da oficina para discussão da Política Nacional de Educação Ambiental (Pnea) alcançou os objetivos esperados. No que se refere ao estudo dela, verificamos que os professores presentes na pesquisa participaram ativamente da leitura do texto da lei, a qual foi acompanhada de discussões sobre temas polêmicos abordados pela política. A forma de inserção da EA em contextos escolares, a responsabilidade de se promover a EA, a formação de professores em EA, a fiscalização do cumprimento das orientações da Pnea e a participação ativa da sociedade diante dos problemas ambientais foram os temas que emergiram com 
maior intensidade nas discussões promovidas pelo grupo de professores da escola estudada.

Como citado anteriormente, foi constatado que oito dos nove professores participantes da oficina nunca tinham lido o texto da Pnea na íntegra, tampouco discutido seu conteúdo. Apenas a professora Teta conhecia o texto da lei devido a sua participação em um curso de especialização em EA. Ao realizar a leitura da Pnea, observamos que o grupo de professores se envolveu efetivamente nas discussões, utilizando suas experiências e concepções para defender seus pontos de vista. Desse modo, o processo de interpretação da Pnea pelos participantes do estudo emergiu da leitura que fizeram do texto da lei, influenciado pelas ideias dessa política, que já permeiam o contexto em que eles estão inseridos, pois, segundo Mainardes e Gandin (2013), ao chegar ao contexto escolar, o texto da política é reinterpretado pelos docentes no processo da produção do currículo na escola.

Apesar de a Pnea ter sido instituída há cerca de vinte anos, verificamos que o documento não fôra ainda estudado pela maioria dos participantes da pesquisa e que os momentos de discussão sobre temáticas ambientais na escola analisada se limitam à participação em datas comemorativas ou a ações isoladas de professores. Dessa forma, percebemos que, nessa escola, os docentes não debatem sobre EA porque não são instigados e não se criam condições para que ocorram discussões dentro da instituição sob uma concepção de escola como espaço de criação de políticas, concepção defendida por Ball, Maguire e Braun (2016). Diante disso, constatamos que os professores envolvidos no estudo só conversam sobre EA se forem estimulados a fazê-lo. Entretanto, esse estímulo deve vir acompanhado pela disponibilização de espaços, de tempo e de materiais para oportunizar o debate entre os docentes e a construção de novos conhecimentos acerca da questão ambiental.

No que se refere à análise crítica do texto da Pnea, verificamos que a maior parte dos professores da escola estudada não discordou de suas orientações. Nesse sentido, percebemos que há, na escola, concepções que enxergam a lei como um documento acabado, inalterável, correto e que deve ser cumprido. Dessa forma, poucos participantes discordaram de trechos da Pnea, emitindo posicionamentos críticos em suas análises.

Com base na análise dos dados, constatamos que algumas das orientações trazidas pela Lei Federal nº 9.795/99 chegaram aos docentes da escola estudada de forma empírica, sem o conhecimento das bases teóricas expressas no texto da política. Contudo, entendendo que a dinâmica da construção do currículo em EA perpassa por diferentes contextos que se influenciam mutuamente, é extremamente necessário que os professores deliberem sobre o conteúdo dos documentos oficiais que orientam os rumos da EA e discutam sobre como tais textos rebatem dentro da escola no processo da produção do currículo. 


\section{Referências}

AZEVEDO, L. V.; COSTA, D. R. T. R.; SANTOS, J. R. Política Nacional de Educação Ambiental: análise de sua aplicação em projetos de pesquisa e extensão de instituições públicas de ensino. Ciência e Natura, Santa Maria, RS, v. 39, n. 3, p. 701-722, set./dez. 2017.

BALL, S. J.; MAGUIRE, M.; BRAUN, A. Como as escolas fazem as políticas: atuação em escolas secundárias. Tradução: Janete Bridon. Ponta Grossa: Editora UEPG, 2016.

BRASIL. Constituição (1988). Constituição da República Federativa do Brasil. Brasília, DF, 1988.

BRASIL. Lei $\mathrm{n}^{\circ}$ 4.771, de 15 de setembro de 1965. Institui o novo Código Florestal. Diário Oficial da União, Brasília, DF, 16 set. 1965. Seção 1, p. 9529.

BRASIL. Decreto no 5.197, de 3 de janeiro de 1967. Dispõe sobre a proteção à fauna e dá outras providências. Diário Oficial da União, Brasília, DF, 5 jan. 1967. Seção 1, p. 177.

BRASIL. Lei no 6.938, de 31 de agosto de 1981. Dispõe sobre a Política Nacional do Meio Ambiente, seus fins e mecanismos de formulação e aplicação, e dá outras providências. Diário Oficial da União, Brasília, DF, 9 jun. 1981. Seção 1, p. 1120.

BRASIL. Lei no 9.433, de 8 de janeiro de 1997. Institui a Política Nacional de Recursos Hídricos, cria o Sistema Nacional de Gerenciamento de Recursos Hídricos, regulamenta o inciso XIX do art. 21 da Constituição Federal e altera o art. $1^{\circ}$ da Lei $\mathrm{n}^{\circ} 8.001$, de 13 de março de 1990, que modificou a Lei $\mathrm{n}^{\circ}$ 7.990, de 28 de dezembro de 1989. Diário Oficial da União, Brasília, DF, 9 jan. 1997. Seção 1, p. 1.

BRASIL. Lei no 9.605, de 12 de fevereiro de 1998. Dispõe sobre as sanções penais e administrativas derivadas de condutas e atividades lesivas ao meio ambiente, e dá outras providências. Diário Oficial da União, Brasília, DF, 13 fev. 1998. Seção 1, p. 1.

BRASIL. Lei no 9.795, de 27 de abril de 1999. Dispõe sobre a educação ambiental, institui a Política Nacional de Educação Ambiental e dá outras providências. Diário Oficial da União, Brasília, DF, 28 de abr. 1999. Seção 1, p. 1.

BRASIL. Câmara dos Deputados. Projeto de Lei $n^{\circ}$ 3.792, de 6 de maio de 1993. Dispõe sobre a educação ambiental, institui a política nacional de educação ambiental e dá outras providências. Brasília, DF, 1993. Disponível em: <https://www.camara.leg.br/proposicoesWeb/fichadetra mitacao?idProposicao=215990 >. Acesso em: 15 jul. 2020. 
BRASIL. Ministério da Educação (MEC). Conselho Nacional de Educação (CNE). Conselho Pleno (CP). Parecer no 14, de 6 de junho de 2012. Diretrizes Curriculares Nacionais para a Educação Ambiental. Diário Oficial da União, Brasília, DF, 15 jun. 2012. Seção 1, p. 18.

BRASIL. Ministério da Educação (MEC). Conselho Nacional de Educação (CNE). Conselho Pleno (CP). Resolução no 2, de 15 de junho de 2012. Estabelece as Diretrizes Curriculares Nacionais para a Educação Ambiental. Diário Oficial da União, Brasília, DF, 18 jun. 2012. Seção 1, p. 70 .

BRASIL. Ministério da Saúde (MS). Conselho Nacional de Saúde (CNS). Resolução no 510, de 7 de abril de 2016. Diário Oficial da União, Brasília, DF, 25 abr. 2016. Seção 1, p. 44.

DIAS, W. R. L.; OLIVEIRA, C. N. N. Reflexão sobre a Lei n 9.975 de abril de 1999 (Política Nacional de Educação Ambiental - Pnea) e a sua prática no Colégio Municipal Odete Nunes Dourado em Irecê-BA: um estudo de caso. Enciclopédia Biosfera, Goiânia, v. 10, n. 18, p. 89-104, abr. 2014.

FARIAS FILHO, E. N. O contexto da prática da educação ambiental: interpretações sobre produção do currículo na escola. 2014. $201 \mathrm{f}$. Dissertação (Mestrado em Ensino das Ciências) - Universidade Federal Rural de Pernambuco, Recife, 2014.

GONZÁLEZ-GAUDIANO, E. Interdisciplinaridade e educação ambiental: explorando novos territórios epistêmicos. In: SATO, M.; CARVALHO, I. Educação ambiental: pesquisa e desafios. Porto Alegre: Artmed, 2005. p. 121-135.

JANKE, N. Política Nacional de Educação Ambiental: contradições e disputas. 2012. 224 f. Tese (Doutorado em Educação para a Ciência) Faculdade de Ciências, Universidade Estadual Paulista, Bauru, 2012.

LAYRARGUES, P. P. A conjuntura da institucionalização da política nacional de educação ambiental. OLAM: Ciência e Tecnologia, Rio Claro, SP, v. 2, n. 1, p. 1-14, abr. 2002.

LOPEZ VELASCO, S. Algumas reflexões sobre a Pnea (Política Nacional de Educação Ambiental, Lei no 9.795, de 27/4/1999). REMEA: Revista Eletrônica do Mestrado em Educação Ambiental, Rio Grande, v. 8, p. 1220, jan./jun. 2002 .

MACEDO, E. Temas transversais. Química na Nova Escola, São Paulo, n. 8, p. 1-5, nov. 1998.

MAIA, H. J. L. et al. Política Nacional de Educação Ambiental: conceitos, inovações e aplicabilidade. In: CONGRESSO BRASILEIRO DE GESTÃO 
AMBIENTAL, 4., 2013, Salvador. Anais... Salvador: Instituto Brasileiro de Estudos Ambientais, 2013.

MAINARDES, J.; GANDIN, L. A. A abordagem do ciclo de políticas como epistemetodologia: usos no Brasil e contribuições para a pesquisa sobre políticas educacionais. In: TELLO, C.; ALMEIDA, M. L. P. (Org.). Estudos epistemológicos no campo da pesquisa em política educacional. Campinas: Mercado de Letras, 2013. p. 143-167.

MARCONDES, M. I.; FREUND, C.; LEITE, V. F. Uma nova abordagem ao estudo das políticas educacionais. Práxis Educativa, Ponta Grossa, v. 12, n. 3, p. 1028-1034, set./dez. 2017.

PEDRINI, A. G. As políticas públicas nacionais com educação ambiental no Brasil: evolução e perspectivas. In: GRUPO Pesquisador em Educação Ambiental, Comunicação e Arte. Cuiabá, 2002. Disponível em: <http:// www.ufmt.br/gpea/pub/pedrini_pp_ea.pdf >. Acesso em: 2 abr. 2014.

POMBO, O.; LEVY, T.; GUIMARÃES, H. A interdisciplinaridade: reflexão e experiência. 2. ed. Lisboa: Campo das Letras, 1994.

RODRIGUES, J. N.; GUIMARÃES, M. Políticas públicas e educação ambiental na contemporaneidade: uma análise crítica sobre a política nacional de educação ambiental (Pnea). Ambiente \& Educação, Rio Grande, v. 15, n. 2, p. 13-30, 2010.

VIEZZER, M. L. Somos todos aprendizes: lembranças da construção do tratado de educação ambiental. In: TRATADO de Educação Ambiental para Sociedades Sustentáveis e Responsabilidade Global. Joinville, 20 jun. 2008. Disponível em: <https://tratadodeea.blogspot.com/2008/06/ somos-todos-aprendizes-lembranas-da.html> Acesso em: 15 jul. 2020.

Recebido em 2 de fevereiro de 2019.

Aprovado em 31 de janeiro de 2020. 